\title{
Set of Activities Addressed for Elementary School Students: Cells and the Genetic Material
}

\author{
E.M. Miranda; F.M. Chiari; A.C.R. Guerra; N.F. dos Santos; L.M. Beltramini; N.R.S. Bossolan
}

Centro de Biotecnologia Molecular Estrutural (CBME/CEPID/FAPESP) - Instituto de Física de São Carlos USP, São Carlos, SP. e-mail: nelma@if.sc.usp.br

The time lag between the progresses in the area of molecular biology reached in the last years and the schools science curricula can be reduced through initiatives of the university regarding the dissemination of sciences. Inside of this context, one of the major objectives of the CBME has been the scientific education and dissemination on Molecular Biosciences. Among the strategies organized to promote the dissemination of this area, the Scientific Dissemination Coordination of CBME developed a set of playful activities for students from public and private elementary schools (7th and 8th grades). As a first step science teachers were interviewed in order to indicate which topics related to molecular biosciences they usually include in their curricula planning. The approach considered in the elaboration of the set of activities was the construction of knowledge of the concepts related to topics as cell types, their structures and organelles, and the importance of the nucleus and DNA. The set was offered to 170 students. Students from private schools were evaluated by their performance through the classes, which were registered by the notes of the instructors. Students from public schools were evaluated through questionnaires containing basic concepts on the theme applied before (pre-test) and after (post-test) the set of activities in order to measure, respectively, the previous and acquired knowledge. The programming accomplished at the public school was partially modified due to the absence of a laboratory, microscopes and a room of computers, without, however, to alter the objectives and content of the activities. The comparative analysis of the pre- and post-tests revealed that, in this latter, there was an increase of the average percentage of correct answers and an improvement on the elaboration of the answers. These results assure the efficiency of the program and the methodology used. The students considered the organization, contents and methodology employed in the course as being satisfactory. Support by CNPq and FAPESP 